\title{
Analysis of Radiative Transfer Equation for Measurement of Particulate Matter Emitted from Coal-Fired Power Plants
}

\section{Euntaek Lee}

Department of Mechanical System Engineering, Kumoh National Institute of Technology

(Received April 23, 2019; Revised July 22, 2019; Accepted July 31, 2019)

Objectives: This study represents the analysis of radiative transfer equation (RTE) for measurement of particulate matter emitted from coal-fired power plants. Generally, the light extinction method is used to measure the mass concentration of particulate matter.

Methods: In this paper, the two-flux approximation is used to solve the radiative transfer equation and obtain the nondimensional incident radiation within emission outlet. Also, the radiation characteristics of the particulate matter are predicted with Lorenz-Mie theory. The particulate matter has three size distributions with geometric mean particle diameters $10 \mathrm{~nm}, 100 \mathrm{~nm}$ and $1 \mu \mathrm{m}$.

Results and Discussion: Absorption and scattering cross-sections and asymmetric factor are predicted as a function of wavelength and compared with respect to geometric mean particle diameters. Also, mass absorption and scattering cross-sections are predicted for conversion of particulate matter mass concentration. The nondimensional incident radiations at the emission outlet are calculated and compared with that of Beer-Lambert law for mass concentration $10 \mathrm{mg} / \mathrm{m}^{3}$ and $50 \mathrm{mg} / \mathrm{m}^{3}$.

Conclusions: Beer-Lambert law is valid for low scattering medium compared with absorption of medium. Nondimensional incident radiations at the emission are highly affected by the radiation characteristics of particulate matter.

Key Words : Particulate matter, Light scattering, Light extinction, Radiative transfer equation, Radiation characteristics 


\title{
연구논문
}

\section{석탄 화력 발전소 배출 미세먼지 측정을 위한 복사전달 방정식 해석}

\section{이은택}

\author{
금오공과대학교 기계시스템공학과
}

목적 : 본 연구에서는 화력 발전소에서 배출되는 미세먼지 측정을 위한 복사전달 방정식의 해석을 알아보고자 한다. 일반적으로 광산란법이나 광소멸법은 미세먼지 농도 측정에 사용된다.

방법: 이 논문에서는 two-flux approximation을 사용하여 복사전달 방정식을 풀고 무차원 입사 복사를 구하여 보았 다. 또한, Lorenz-Mie 이론을 사용하여 미세먼지 입자의 복사특성을 예측하여 보았다. 미세먼지 입자의 크기 분포 는 기하 평균 입경 지름 $10 \mathrm{~nm}, 100 \mathrm{~nm}$ 그리고 $1 \mu \mathrm{m}$ 의 3가지 경우를 고려하였다.

결과 및 토의 : 흡수, 산란 단면과 비대칭 인자를 파장의 함수로 예측하고 서로 다른 기하 평균 입경에 대하여 비교 하였다. 또한 미세먼지의 질량 농도를 사용하기 위하여 질량 흡수, 산란 단면을 구하였다. 배출에서 무차원 입사 복사를 계산하고 질량 농도 $10 \mathrm{mg} / \mathrm{m}^{3}$ 와 $50 \mathrm{mg} / \mathrm{m}^{3}$ 에 대하여 Beer-Lambert와 비교하였다.

결론 : 입자의 흡수와 비교하여 산란의 영향이 적을 때 Beer-Lambert 법칙이 타당하다는 것을 알아냈다. 그리고 무차원 입사 복사는 미세먼지의 복사 특성에 큰 영향을 받는다는 사실을 알아냈다.

주제어: 미세먼지, 광소멸, 광산란, 복사전달 방정식, 복사특성

\section{1. 서론}

많은 에너지 수요와 그에 따른 생산으로 인하여 화석 연 료의 연소를 이용한 발전이 급격하게 늘어났다. 화석 연료 의 연소를 이용한 발전은 배기가스로 미세먼지(particulate matter, $\mathrm{PM})$, 질소산화물(NOx)과 황산화물( $\mathrm{SOx})$ 등을 배출 한다. 이와 같은 대기오염 물질 중에서 미세먼지에 관한 관 심이 증가하고 있다. 미세먼지는 일반적으로 지름 $10 \mu \mathrm{m}$ 미만의 PM10(미세먼지)과 지름 $2.5 \mu \mathrm{m}$ 미만의 PM2.5(초미 세먼지)로 구별된다. 작은 미세먼지는 폐와 혈관 등에 침투 가능하여 여러 가지 질병의 원인이 될 수 있다. 따라서 세 계보건기구(WHO) 국제암연구소(IARC)는 2013년에 미세먼 지를 1 급 발암물질로 지정하였다. 미세먼지 배출원에서 배 출을 측정하고 배출량을 줄이려는 다양한 연구들이 진행 중이다. ${ }^{14)}$ Mylläri et al. ${ }^{5)}$ 는 발전소 보일러의 배기가스의 성분을 측정하고 미세먼지 입자의 크기 분포를 측정하였 다. Eidhammer et al. ${ }^{6}$ 는 공기 중의 먼지에 대한 굴절률과 크기를 $40^{\circ}$ 와 $74^{\circ}$ 로 산란된 빛을 측정하여 구하였다. Zhao et al. ${ }^{7)}$ 는 층류 예혼합 에틸렌-산소-아르곤 화염에서 soot 입 자의 크기 분포를 측정하고 시뮬레이션 결과와 비교하였 다. Meland et al. ${ }^{8}$ 은 $470 \mathrm{~nm}, 550 \mathrm{~nm}, 660 \mathrm{~nm}$ 파장에서 입
자에 의해 산란된 빛을 측정하고 시뮬레이션 결과와 비교 하였다.

배출 미세먼지를 측정하는 방법은 중량농도법, 베타선 측 정법, 광산란법, 광소멸법 등이 있다. ${ }^{9)}$ 이 중에서 비접촉식 광학법인 광산란법과 광소멸법은 실시간 배출 미세먼지를 측정하기에 적합한 방법이다. 광소멸법을 이용한 여러 연 구에서 Beer-Lambert 법칙을 사용하여 미세먼지 농도를 측 정하였다. ${ }^{10,11)}$ 또한 광소멸법과 광산란법을 이용한 미세먼 지 농도 측정은 산란 또는 소멸된 빛을 측정하고 중량농도 법과 비교 후 보정계수를 산정하는 방법을 사용한다. ${ }^{2)}$ 다 양한 배출원에서의 미세먼지 입자의 복사특성 변화, 배기 가스 온도 및 습도 그리고 Beer-Lambert 법칙의 정확도 때 문에 보정계수가 요구된다. 본 논문에서는 Beer-Lambert 법 칙의 제한사항에 대하여 알아보고 더 정확한 미세먼지 농 도 측정을 위한 복사전달 방정식 해석 및 결과를 비교하였 다. 발전소 배출 미세먼지의 광학적 또는 복사특성은 연소 조건과 연료 등의 다양한 요인에 큰 영향을 받게 된다. 따 라서 정확한 값을 얻기 위하여 실제 측정을 통하여 구할 수 있으나, 본 연구에서는 미세먼지가 완전한 구 형태를 가 지고 있다고 가정하고 Lorenz-Mie 이론 ${ }^{13)}$ 을 이용하여 복사 특성을 계산하였다. 그리고 미세먼지와 빛의 상호작용을 


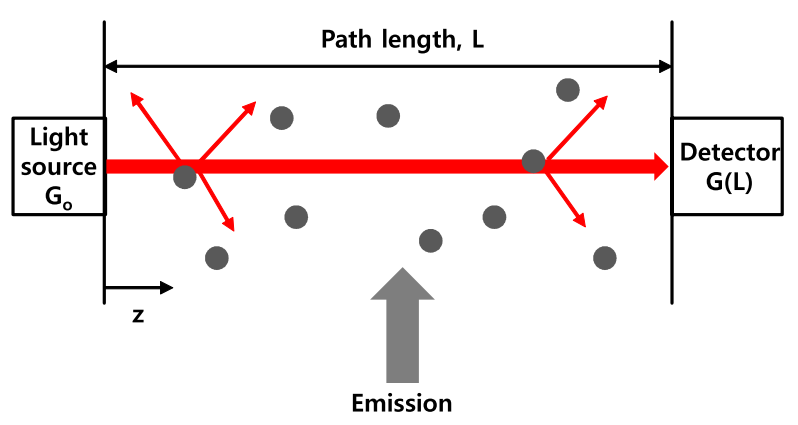

Fig. 1. Schematic diagram of light extinction method for measurement of particulate matter.

알아보기 위하여 two-flux approximation ${ }^{14)}$ 을 사용하여 복사 전달 방정식을 풀어보았다.

\section{2. 이론}

\section{1. 복사전달 방정식}

광소멸법을 이용한 미세먼지 측정의 계략도를 Fig. 1 에 나타냈다. 광원 또는 레이저로부터 나온 빛이 배기가스를 지나간다. 미세먼지 입자는 빛을 산란, 흡수하여 빛의 세기 를 점점 감소시킨다. 측정부에 도달한 빛의 세기를 이용하 여 미세먼지 입자의 농도를 측정하는 방식이 광소멸법이 다. 복사전달 방정식은 빛이 산란, 흡수하는 매질을 통과할 때의 빛의 세기 변화를 나타내는 방정식이고 아래와 같이 나타낼 수 있다. ${ }^{15)}$

$$
\begin{aligned}
& \frac{d I_{\lambda}(r, \hat{s})}{d s}= \\
& -\kappa_{\lambda}(r) I_{\lambda}(r, \hat{s})-\sigma_{s \lambda}(r) I_{\lambda}(r, \hat{s})+\frac{\sigma_{s \lambda}(r)}{4 \pi} \int_{4 \pi} I_{\lambda}\left(r, \widehat{s}_{l}\right) \Phi_{\lambda}\left(\widehat{s_{l}}, \hat{s}\right) d \Omega_{i}
\end{aligned}
$$

여기서 $I$ 는 빛의 세기, 하첨자 $\lambda$ 는 파장, $r$ 은 위치, $s$ 는 빛 의 방향, $\kappa$ 는 흡수계수, $\sigma_{s}$ 는 산란계수, $\Phi$ 는 산란 위상 함 수를 각각 나타낸다. 또한, 흡수계수와 산란계수의 합을 소 멸계수 $\left(\beta=\kappa^{+} \sigma_{s}\right)$ 로 표현한다. 식(1)의 좌변은 빛의 방향 $s$ 에 대한 빛의 세기 $I$ 의 변화율을 나타내고 우변의 첫 번째 항 은 입자의 흡수에 의한 빛의 감소, 두 번째 항은 산란에 의 한 빛의 감소 그리고 마지막 항은 다른 방향의 빛이 산란 하여 $s$ 방향으로 들어오는 빛의 세기를 나타낸다. 위의 복사 전달 방정식을 풀기 위한 다양한 방법이 있다. ${ }^{15)}$

\section{2. 입자의 복사특성}

복사전달 방정식을 풀기 위하여 미세먼지 입자의 복사특 성을 파악하여야 한다. 미세먼지 입자를 구 형태와 크기 분 포가 있다고 가정하였다. 일반적인 입자 크기 분포는 로그 정규 분포를 따르며 아래와 같다. ${ }^{16)}$

$$
N\left(d_{p}\right)=\frac{1}{d_{p} \sqrt{2 \pi} \ln \sigma_{g}} \exp \left[-\left(\frac{\ln \left(d_{p} / d_{g}\right)}{\sqrt{2} \ln \sigma_{g}}\right)^{2}\right]
$$

여기서, $d_{p}$ 는 입자의 지름, $d_{g}$ 는 기하 평균 입경, $\sigma_{g}$ 는 기 하 표준 편차이다. 로그 정규 분포를 따르는 크기를 가진 미세먼지 입자의 흡수계수와 산란계수는 다음과 같다. ${ }^{13)}$

$$
\begin{aligned}
& \kappa_{\lambda}=\int_{0}^{\infty} C_{a b s, \lambda}\left(d_{p}\right) N\left(d_{p}\right) \mathrm{d} d_{p}=\bar{C}_{a b s, \lambda} N_{T}=\bar{A}_{a b s, \lambda} X \\
& \sigma_{\lambda}=\int_{0}^{\infty} C_{s c a, \lambda}\left(d_{p}\right) N\left(d_{p}\right) \mathrm{d} d_{p}=\bar{C}_{s c a, \lambda} N_{T}=\bar{S}_{s c a, \lambda} X
\end{aligned}
$$

여기서, $C_{a b s}$ 와 $C_{s c a}$ 는 한 입자의 흡수, 산란 단면적이다. $\bar{C}_{a b s}$ 와 $\bar{C}_{s c a}$ 는 전체 입자에 대한 평균 단면적, $\bar{A}_{a b s}$ 와 $\bar{S}_{s c a}$ 는 평균 질량 흡수, 산란 단면적이다. $N_{T}$ 는 단위 부피당 총 입자 개수이고, $X$ 는 단위 부피당 입자의 질량이다. 미세먼 지 입자를 완전한 구 형태로 가정하고 Maxwell 방정식의 해석적인 해인 Lorenz-Mie 이론을 사용하여 입자의 평균 흡수, 산란 단면적과 비대칭 인자를 얻을 수 있다. ${ }^{13)}$ 비대 칭 인자를 Henyey-Greenstein 위상 함수에 적용해 산란 위 상 함수를 아래의 식을 이용하여 구할 수 있다. ${ }^{13)}$

$$
\Phi_{\lambda}(\theta)=\frac{1-g_{\lambda}{ }^{2}}{\left[1+g_{\lambda}{ }^{2}-2 g_{\lambda} \cos \theta\right]^{3 / 2}}
$$

여기서 $g_{\lambda}$ 는 비대칭 인자이고 $\theta$ 는 입자로 들어가는 빛의 방향과 입자에 의해서 산란된 빛의 방향 사이의 각도이다. 비대칭 인자의 크기는 -1 에서 1 사이의 값을 가진다. ${ }^{13)}$ 비 대칭 인자가 -1에 가까울수록 후방산란이 주로 발생하고 1 에 가까울수록 전방산란이 주로 발생하게 된다. ${ }^{13)}$ 그리고 비대칭 인자가 0 인 경우는 등방산란을 의미한다. 미세먼지 입자의 농도를 나타낼 때 개수 밀도 $\left(N_{T}\right)$ 또는 질량 농도 $(X)$ 를 사용한다. 그에 따라서 미세먼지의 복사특성인 평균 흡 수, 산란 단면적과 평균 질량 흡수, 산란 단면적의 관계는 다음과 같이 나타낼 수 있다. ${ }^{14)}$

$$
\bar{C}_{a b s, \lambda}=\bar{A}_{a b s, \lambda} \bar{V} \rho \quad \bar{C}_{s c a, \lambda}=\bar{S}_{s c a, \lambda} \bar{V} \rho
$$

여기서 $\bar{V}$ 는 미세먼지 입자의 평균 부피이고, $\rho$ 는 미세 먼지 입자의 밀도다.

\section{3. 복사전달 방정식 해석}

복사전달 방정식 식(1)에서 우변 마지막 항을 무시하고 소멸계수 $\beta$ 를 사용하면 다음과 같이 쓸 수 있다.

$$
\frac{d I_{\lambda}(r, \hat{s})}{d s}=-\beta_{\lambda}(r) I_{\lambda}(r, \hat{s})
$$


이 미분 방정식의 해가 Beer-Lambert 법칙이고 다음과 같 이 나타낼 수 있다.

$$
\frac{I_{\lambda}(z)}{I_{0 \lambda}}=e^{-\beta_{\lambda} Z}
$$

여기서 $I_{0 \lambda}$ 는 광원에서 나가는 파장 $\lambda$ 인 빛의 세기이고 $I_{\lambda}$ 는 빛이 소멸계수 $\beta$ 를 가진 매질을 길이 $z$ 만큼 통과하였을 때의 세기이다. Beer-Lambert 법칙은 복사전달 방정식에서 다른 방향에서 산란되어 들어오는 빛을 나타내는 마지막 항을 무시하였기 때문에 산란된 빛이 진행 중인 빛에 더해 지는 현상을 나타낼 수가 없다. 따라서 Beer-Lambert 법칙 은 한번 산란된 빛은 소멸되어 다른 곳에 아무런 영향을 줄 수 없을 때 사용할 수 있다. 하지만 일반적인 입자에 의 한 빛의 산란은 빛이 다른 방향 또는 진행 방향(전방산란) 및 반대 방향(후방산란)으로 산란되어 다른 곳에 영향을 준 다. 임의의 지점 $\mathrm{z}$ 에서 모든 방향에서 들어오는 빛의 강도 인 입사 복사는 다음과 같다. ${ }^{15)}$

$$
G_{\lambda}(z)=\int_{4 \pi} I_{\lambda}(r, \hat{s}) d \Omega
$$

길이가 $\mathrm{L}$ 인 산란, 흡수하는 매질에서 1 차원 복사전달 방 정식을 two-flux approximation ${ }^{14)}$ 을 이용하여 풀어보았다. 임의의 지점에서 입사 복사와 광원에서의 입사 복사의 비인 무차원 입사 복사를 아래의 식을 이용하여 구할 수 있다. ${ }^{14)}$

$$
\frac{G_{\lambda}(z)}{G_{0 \lambda}}=2 \frac{\left(1+\alpha_{\lambda}\right) e^{\delta_{\lambda}(L-z)}-\left(1-\alpha_{\lambda}\right) e^{-\delta_{\lambda}(L-z)}}{\left(1+\alpha_{\lambda}\right)^{2} e^{\delta_{\lambda} L}-\left(1-\alpha_{\lambda}\right)^{2} e^{-\delta_{\lambda} L}}
$$

여기서 선형산란계수 $\alpha_{\lambda}$ 와 two-flux 소멸계수 $\delta_{\lambda}$ 그리고 후방산란분률 $b_{\lambda}$ 는 다음과 같다. ${ }^{14)}$

$$
\begin{gathered}
\alpha_{\lambda}=\sqrt{\frac{\kappa_{\lambda}}{\kappa_{\lambda}+2 b_{\lambda} \sigma_{s \lambda}}} \quad \delta_{\lambda}=\sqrt{\kappa_{\lambda}\left(\kappa_{\lambda}+2 b_{\lambda} \sigma_{s \lambda}\right)} \\
b_{\lambda}=\frac{1}{2} \int_{\pi / 2}^{\pi} \Phi_{\lambda}(\theta) \sin \theta \mathrm{d} \theta
\end{gathered}
$$

만약 식(11)에서 $\alpha_{\lambda}$ 의 값이 1 이라면 식(10)의 two-flux approximation과 식(8)의 Beer-Lambert 법칙이 같아지게 된 다. 여기서 two-flux approximation의 $\alpha_{\lambda}=1$ 이란 특수한 경우 가 Beer-Lambert 법칙임을 알 수 있다. 또한, $\alpha_{\lambda}$ 가 1 이 되기 위한 조건은 $b_{\lambda}$ 는 0 또는 $\sigma_{s}$ 는 0 인 경우이고 입자에 의한 산란이 없거나 후방산란이 없는 경우에만 Beer-Lambert 법 칙의 적용이 가능하다는 것을 알 수 있다.

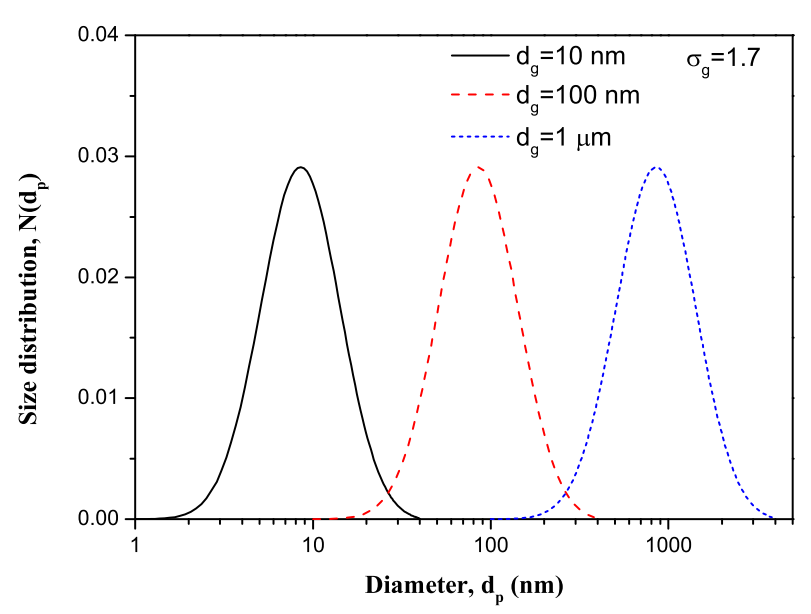

Fig. 2. Size distributions of particulate matter with geometric mean particle diameters $10 \mathrm{~nm}, 100 \mathrm{~nm}$ and $1 \mu \mathrm{m}$.

\section{3. 결 과}

\section{1. 미세먼지 입자의 복사특성 예측}

석탄 화력 발전소에서 발생하는 미세먼지는 주로 soot 입 자이다. ${ }^{16)}$ Soot 입자의 크기는 연소 조건과 발전 설비의 작 동 조건 등 다양한 요소에 의하여 영향을 받게 된다. 본 연 구에서 미세먼지의 크기는 로그 정규 분포를 따르고 기하 평균 입경 $\left(d_{g}\right)$ 이 $10 \mathrm{~nm}, 100 \mathrm{~nm}$ 그리고 $1 \mu \mathrm{m}$ 인 3 가지 경 우에 대하여 알아볼 것이다. 이때 기하 표준 편차 $\left(\sigma_{g}\right)$ 는 1.7 이다.

Fig. 2에 미세먼지 입자 크기 분포를 나타냈다. 이와 같은 분포를 가진 미세먼지 입자의 복사특성을 가시광선 파장 영역(400-700 nm)에서 Lorenz-Mie 이론 ${ }^{13)}$ 을 이용하여 예측 하였다. Soot 입자가 주성분인 미세먼지의 복소 굴절률은 $1.75+\mathrm{i} 0.43^{17)}$ 으로 가정하였다.

Fig. 3은 흡수, 산란 단면적과 비대칭 인자를 보여준다. 흡수와 산란 단면적 모두 기하 평균 입경에 따라서 커다란 차이가 있다는 것을 알 수 있다. 그리고 기하 평균 입경 10 $\mathrm{nm}$ 와 $100 \mathrm{~nm}$ 의 경우 흡수와 산란 단면적이 파장이 커짐에 따라서 감소하는 것을 알 수 있다. 반면에 기하 평균 입경 $1 \mu \mathrm{m}$ 인 경우 흡수와 산란 단면적 모두 파장의 영향이 거의 없음을 알 수 있다. 또한, 기하 평균 입경 $100 \mathrm{~nm}$ 의 흡수와 산란 단면적의 값은 모두 대략 $10^{-15}-10^{-14} \mathrm{~m}^{2}$ 그리고 $1 \mu \mathrm{m}$ 의 값은 $10^{-12} \mathrm{~m}^{2}$ 정도로 흡수와 산란 단면적 서로 비슷한 값을 갖는다. 하지만 $10 \mathrm{~nm}$ 에서는 흡수 단면적은 $10^{-18}-10^{-17}$ $\mathrm{m}^{2}$ 의 값을 갖고 산란 단면적의 값은 $10^{-21}-10^{-20} \mathrm{~m}^{2}$ 로 $10^{3}$ 배 정도의 차이를 보인다. 비대칭 인자도 기하 평균 입경에 따 라서 큰 차이가 있다. 기하 평균 입경 $10 \mathrm{~nm}$ 의 입자들은 비대칭 인자의 값이 0.8 정도로 등방산란을 하고, $1 \mu \mathrm{m}$ 입 자들은 비대칭 인자의 값이 0.01 정도로 강한 전방산란을 한다.

일반적으로 미세먼지 입자의 농도를 나타내는 방법은 


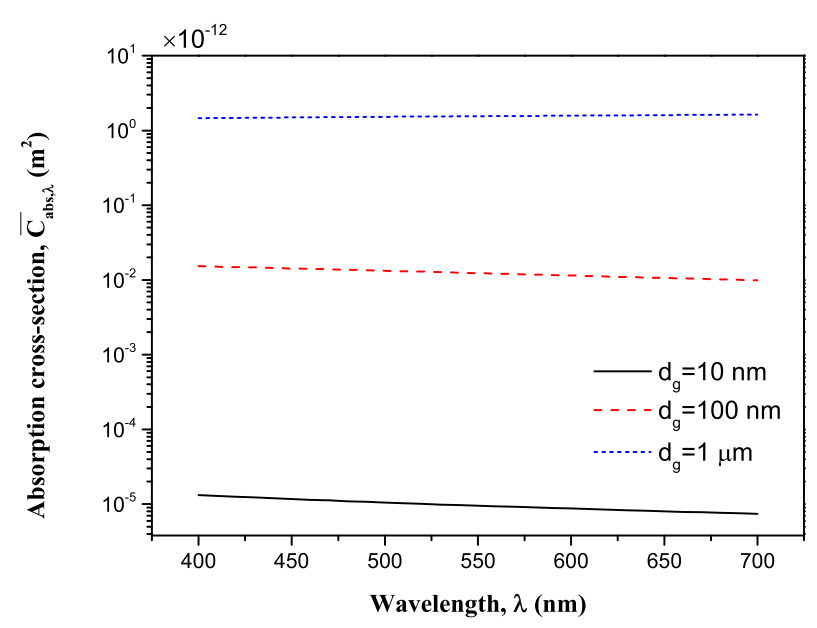

(a)

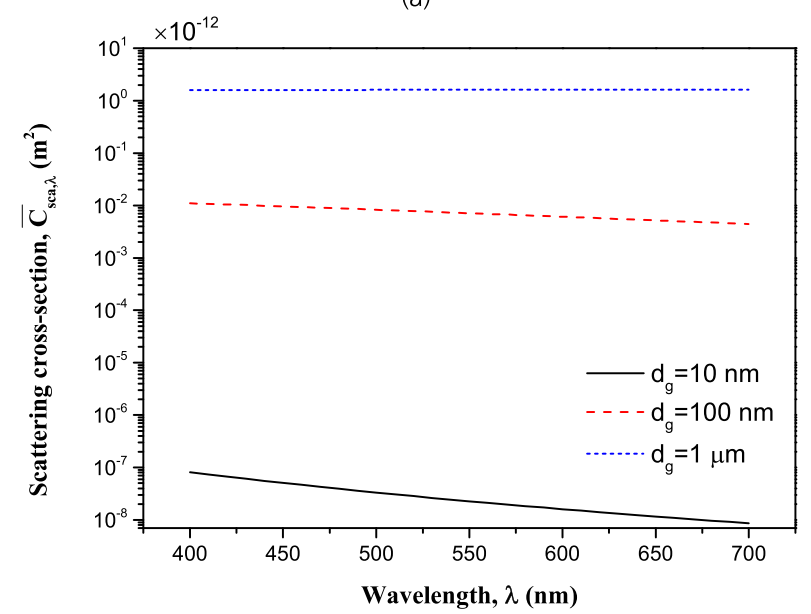

(b)

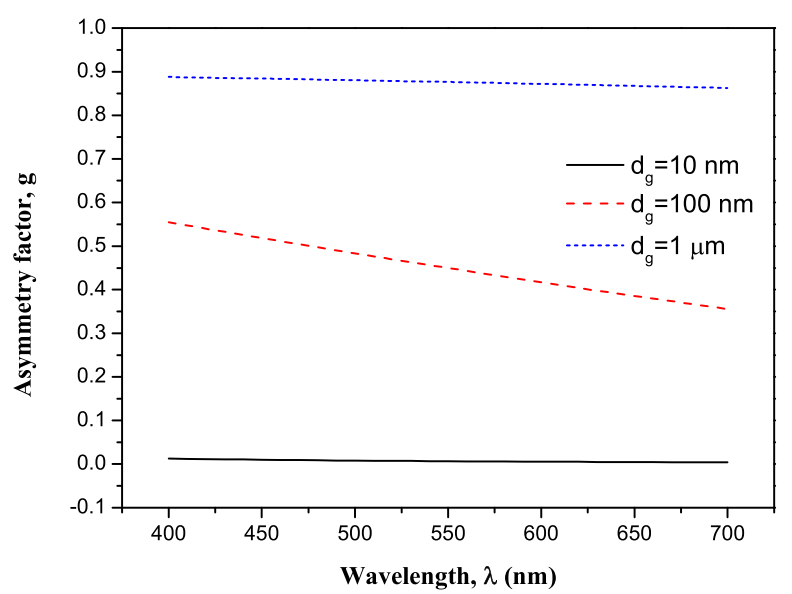

(c)

Fig. 3. (a) Absorption cross-section (b) Scattering cross-section (c) Asymmetry factor with geometric mean particle diameters $10 \mathrm{~nm}, 100 \mathrm{~nm}$ and $1 \mu \mathrm{m}$.

단위 부피당 미세먼지 입자의 질량인 질량 농도이다. 질량 농도를 사용하여 흡수계수와 산란계수를 구하기 위하여 흡수, 산란 단면적을 질량 흡수, 산란 단면적으로 변환하 였다. 이때 미세먼지 입자의 평균 부피는 $10 \mathrm{~nm}$ 의 경우

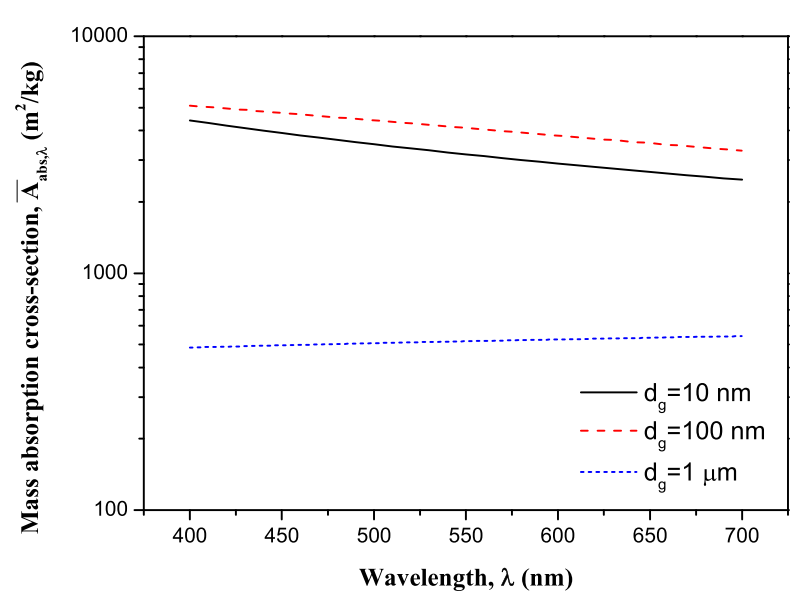

(a)

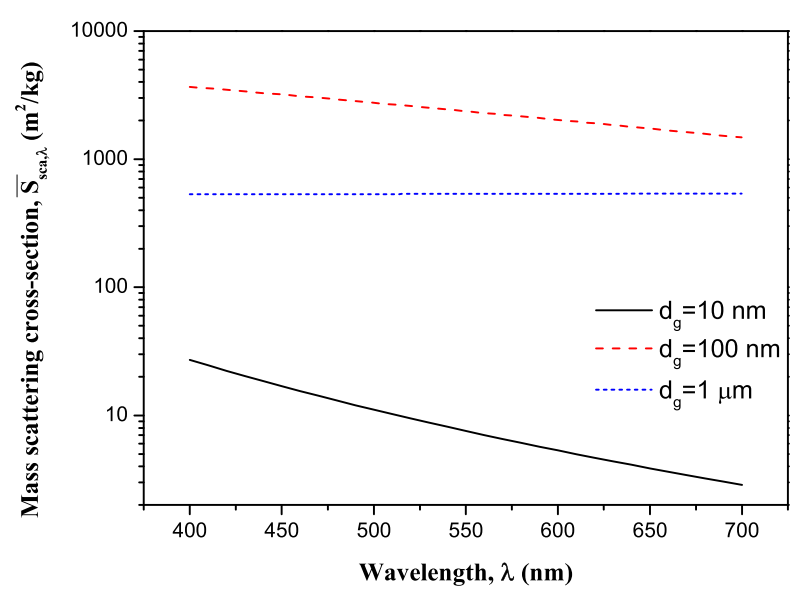

(b)

Fig. 4. (a) Mass absorption cross-section (b) Mass scattering cross-section with geometric mean particle diameters $10 \mathrm{~nm}, 100 \mathrm{~nm}$ and $1 \mu \mathrm{m}$.

$1.58 \times 10^{-24} \mathrm{~m}^{3}, 100 \mathrm{~nm}$ 의 경우 $1.58 \times 10^{-21} \mathrm{~m}^{3}$ 그리고 $1 \mu \mathrm{m}$ 의 경우 $1.58 \times 10^{-18} \mathrm{~m}^{3}$ 이다. 또한, 미세먼지 입자의 밀도는 $1900 \mathrm{~kg} / \mathrm{m}^{3}{ }^{16}$ 으로 가정하였다. Fig. 4는 평균 질량 흡수, 산란 단면적을 보여준다. 각각의 평균 입자 부피에 따라서 경향이 달라지는 것을 볼 수 있다.

\section{2. 복사전달 방정식 해석}

복사전달 방정식을 two-flux approximation을 사용하여 배 기가스 출구에서 풀어보았다. Fig. 1 에 보인 것과 같이 배기 가스가 지나가고 한쪽 끝의 광원에서 빛이 배기가스를 지 나간다. 국내 석탄 화력 발전소의 미세먼지 배출 기준은 2001년 7월 이전 설치 시설의 경우 $25 \mathrm{mg} / \mathrm{m}^{3}$, 이후 설치는 $20 \mathrm{mg} / \mathrm{m}^{3}$ 의 허용 기준을 가지고 있고, 신규시설의 경우 10 $\mathrm{mg} / \mathrm{m}^{3}$ 의 허용 기준을 가지고 있다. 하지만 그 기준이 점차 강화되는 추세이다. 본 연구에서는 배기가스에 포함된 미 세먼지의 질량 농도는 $10 \mathrm{mg} / \mathrm{m}^{3}$ 과 $50 \mathrm{mg} / \mathrm{m}^{3}$ 의 두 가지 경 우에 대하여 알아보았다. 광원에서 나오는 빛의 세기와 빛 
의 경로상 임의의 지점에서 빛의 세기의 비인 무차원 입사 복사를 구할 것이다. 그리고 Beer-Lambert 법칙과의 차이도 알아볼 것이다. 또한, 미세먼지 배출구의 지름을 대략 $5 \mathrm{~m}^{18)}$ 정도로 가정하여 광원에서 $\mathrm{L}=5 \mathrm{~m}$ 떨어진 측정부에서의 파 장별 무차원 입사 복사를 구하여 파장에 따른 값의 차이를 알아볼 것이다.

Fig. 5는 무차원 입자 복사를 경로 길이의 함수로 계산 된 결과를 보여준다. 모든 입자에 대하여 미세먼지의 질량 농도가 커졌을 경우 빛의 도달하는 양이 적어진다. 기하 평균 입경 $10 \mathrm{~nm}$ 를 제외한 입자 크기에 대하여 two-flux approximation의 결과와 Beer-Lambert 법칙의 결과가 모든 파장 영역에 걸쳐서 차이가 있다. 기하 평균 입경 $10 \mathrm{~nm}$ 의 경우 미세먼지 입자 복사특성 예측에서 알 수 있듯이 흡수 단면적이 산란 단면적의 $10^{3}$ 배만큼 크게 나타난다. 입자의 흡수계수가 산란계수와 비교하여 매우 크기 때문에 전체 파장에 걸쳐서 two-flux approximation의 계수 $\alpha_{\lambda}$ 값이 거의

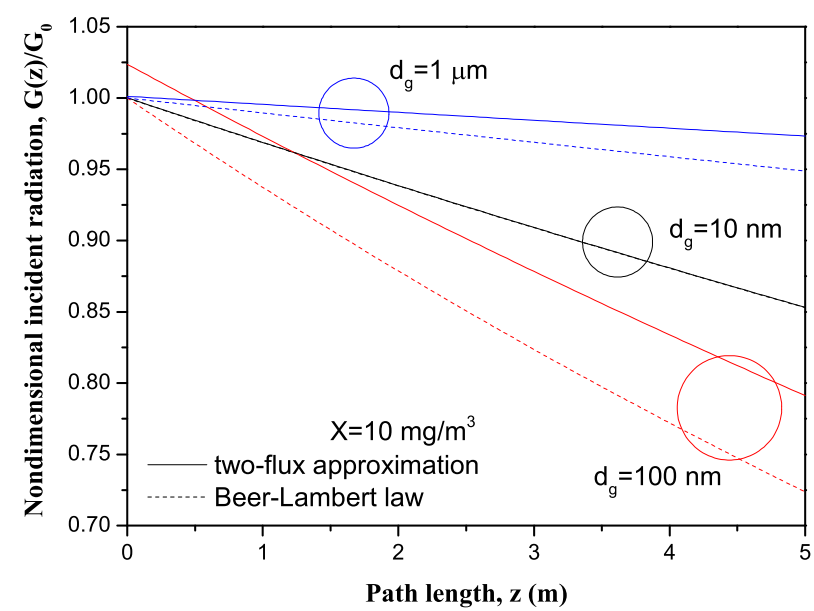

(a)

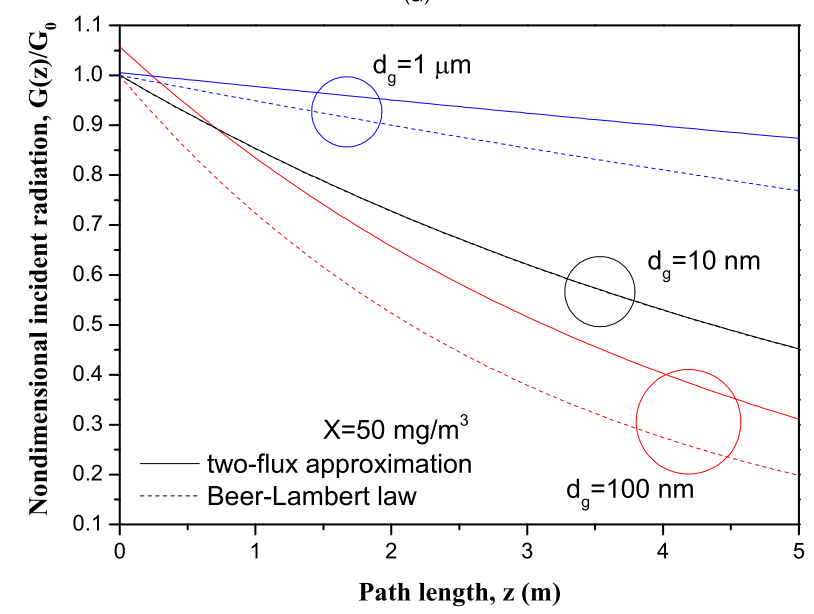

(b)

Fig. 5. Nondimensional incident radiation as function of path length for mass concentration (a) $10 \mathrm{mg} / \mathrm{m}^{3}$ (b) 50 $\mathrm{mg} / \mathrm{m}^{3}$ with geometric mean particle diameters 10 $\mathrm{nm}, 100 \mathrm{~nm}$ and $1 \mu \mathrm{m}$.
1 에 가까운 값을 가진다. 따라서 two-flux approximation의 결과와 Beer-Lambert 법칙의 결과가 거의 같게 나타난다. 측정부에서 기하 평균 입경 $1 \mu \mathrm{m}$ 의 무차원 입사 복사가 가 장 크게 나타나고 다음으로 $10 \mathrm{~nm}$ 와 $100 \mathrm{~nm}$ 의 입자가 작 은 값을 갖는다. 같은 질량 농도에 대하여 입자 크기와 측 정부에서의 빛의 세기와는 순서가 일치하지 않는다. 또한, 기하 평균 입경 $100 \mathrm{~nm}$ 는 광원 근처에서 1 보다 큰 값을 갖 는다. 그 이유는 약간의 후방산란으로 광원 근처의 입자들 이 광원 방향으로 빛을 산란하기 때문이다. $10 \mathrm{~nm}$ 의 경우 등방산란으로 그 영향이 상쇄되고, $1 \mu \mathrm{m}$ 의 경우는 강한 전 방산란으로 후방산란이 거의 발생하지 않는다.

Fig. 6는 측정부의 무차원 입사 복사를 파장의 함수로 계 산된 결과를 보여준다. 기하 평균 입경 $1 \mu \mathrm{m}$ 의 무차원 입 사 복사 값은 가시광선 영역에서 파장의 변화와 상관없이 거의 비슷한 값을 갖는다. 다른 결과들은 파장이 커짐에 따 라서 측정부의 입사 복사가 커진다. 기하 평균 입경 $1 \mu \mathrm{m}$

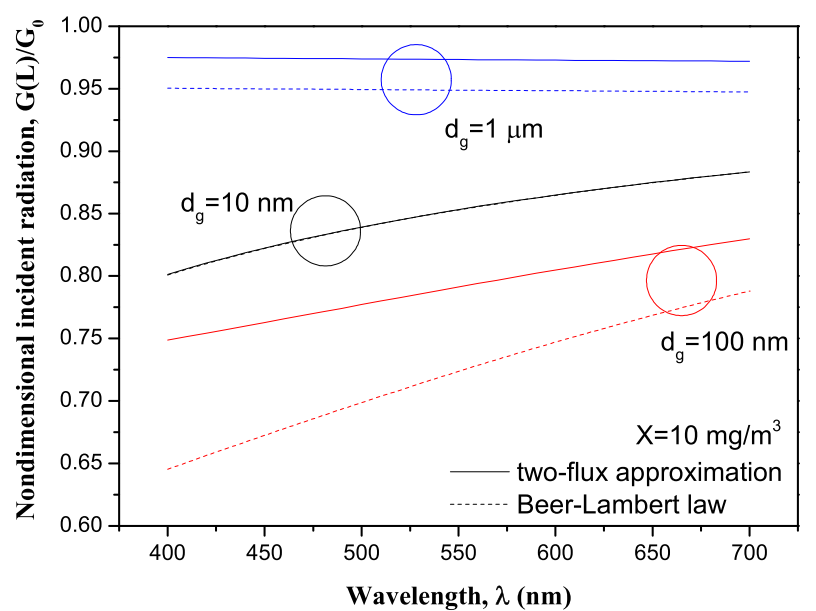

(a)

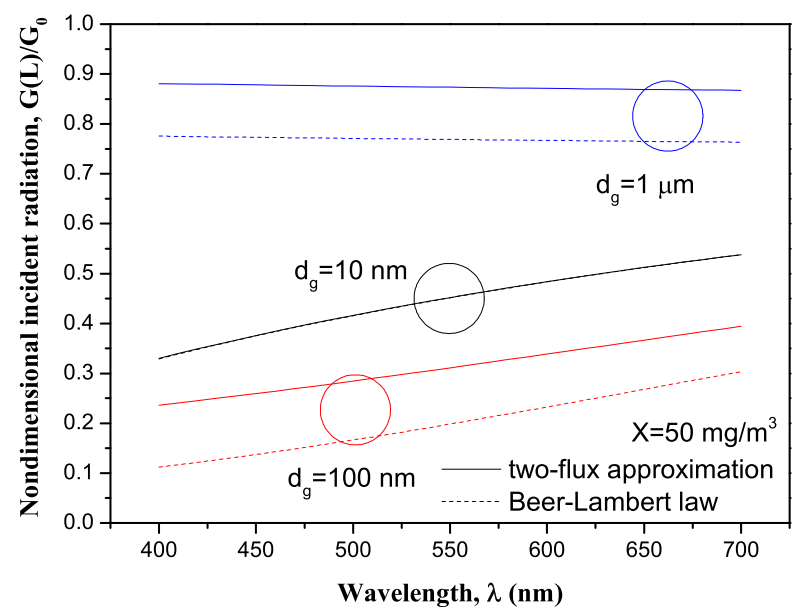

(b)

Fig. 6. Nondimensional incident radiation at detector, $\mathrm{L}=5 \mathrm{~m}$ as function of wavelength for mass concentration (a) $10 \mathrm{mg} / \mathrm{m}^{3}$ (b) $50 \mathrm{mg} / \mathrm{m}^{3}$ with geometric mean particle diameters $10 \mathrm{~nm}, 100 \mathrm{~nm}$ and $1 \mu \mathrm{m}$. 
Table 1. Nondimensional incident radiation of different geometric mean particle diameter at detector, $\mathrm{L}=5 \mathrm{~m}$ at wavelength $400 \mathrm{~nm}, 550 \mathrm{~nm}$ and $700 \mathrm{~nm}$ for mass concentration $10 \mathrm{mg} / \mathrm{m}^{3}$ and $50 \mathrm{mg} / \mathrm{m}^{3}$ using two-flux approximation.

\begin{tabular}{ccccc}
\multirow{2}{*}{ Mass concentration } & Mean diameter & \multicolumn{3}{c}{ Wavelength } \\
\cline { 2 - 4 } & $10 \mathrm{~nm}$ & $400 \mathrm{~nm}$ & $550 \mathrm{~nm}$ & 0.88336 \\
\cline { 2 - 4 } $10 \mathrm{mg} / \mathrm{m}^{3}$ & $100 \mathrm{~nm}$ & 0.8013 & 0.85318 & 0.82972 \\
\cline { 2 - 4 } & $1 \mu \mathrm{m}$ & 0.74864 & 0.79118 & 0.97191 \\
\cline { 2 - 4 } & $10 \mathrm{~nm}$ & 0.97494 & 0.97333 & 0.53789 \\
\hline & $100 \mathrm{~nm}$ & 0.33034 & 0.45206 & 0.39426 \\
& $1 \mu \mathrm{m}$ & 0.23627 & 0.31122 & 0.86724 \\
\hline
\end{tabular}

의 무차원 입사 복사 값이 다른 크기의 입자들과 비교하여 가시광선 파장 영역에서 가장 큰 값을 갖는다. 그 이유는 전방산란에 대한 영향으로 파악된다. 기하 평균 입경 10 $\mathrm{nm}$ 와 $100 \mathrm{~nm}$ 의 경우 질량 농도가 증가함에 따라 모든 파 장에 걸쳐서 측정부의 무차원 입사 복사가 적어지는 것을 확인할 수 있었다. 반면에 기하 평균 입경 $1 \mu \mathrm{m}$ 는 농도가 증가할 때 측정부의 무차원 입사 복사도 증가한다는 것을 알 수 있었다. 큰 미세먼지 입자들은 적은 입자 개수를 갖 고 작은 미세먼지 입자들은 많은 입자 개수를 갖는다. 그러 므로 입자 크기와 무차원 입사 복사가 비례한다고 할 수 없다. 또한, 산란 위상 함수에 따른 전방산란과 후방산란 을 고려하여야만 정확한 미세먼지 입자 농도를 측정할 수 있다. 이와 같은 복사전달 방정식 해석을 통하여 측정부에 도달한 빛의 세기로부터 미세먼지 입자의 농도를 정확하 게 예측할 수 있을 것이다. Remote sensing 방법과 비슷하 게 여러 파장의 빛을 측정하여 각 파장에서 측정된 빛의 세기를 갖는 미세먼지 입자의 농도를 역계산 방법으로 얻 어낼 수 있다. 비슷한 방법으로 미세먼지 입자의 크기를 측 정할 수 있다. ${ }^{19)}$ 서로 다른 미세먼지 농도에 대한 two-flux approximation의 파장별 결과를 Table 1에 나타냈다.

미세먼지 측정을 위한 복사전달 방정식의 해석은 입자의 크기와 개수, 그 크기에 영향을 받는 복사특성 등의 여러 가지 요소를 고려하여야 한다. 따라서 정확한 실시간 미세 먼지 입자의 농도 측정을 위하여 실제적인 미세먼지 입자 의 크기와 굴절률 측정이 요구된다.

\section{4. 결론}

본 연구에서는 화력 발전소 배출 미세먼지 실시간 측정 을 위하여 복사전달 방정식을 해석하여 보았다. Lorenz-Mie 이론을 이용하여 미세먼지의 복사특성을 예측하였고, two-flux approximation을 이용하여 복사전달 방정식을 풀어보았다. 그 결과를 Beer-Lambert 법칙과 비교하여 타당성을 검증하 였다. 입자의 흡수와 비교하여 산란의 영향이 적을 때 Beer-Lambert 법칙이 타당하다는 것을 알아내었다. 또한, 파장별 무차원 입사 복사를 구하여 특정 측정 파장에서 입
자 크기에 따른 입사 복사의 크기를 예측하여 보았다. 미세 먼지 농도 변화에 따른 무차원 입사 복사는 농도가 증가함 에 따라서 항상 감소하지 않고 입자의 복사특성에 영향을 받는다는 사실을 알아내었다. 미세먼지의 복사특성과 복사 전달 방정식 해석은 정확한 실시간 미세먼지 농도 측정에 많은 도움이 될 것으로 기대된다. 그리고 향후 two-flux approximation과 역계산 방법을 결합하고 여러 파장의 빛을 측정하여 복사전달의 해석을 검증하는 연구가 필요할 것으 로 예상된다.

\section{Acknowledgement}

이 연구는 금오공과대학교 학술연구비에 의하여 지원된 논문입니다.

\section{References}

1. S. Kim, J. Bae, K. S. Kim, Dust removal of electrostatic precipitator equipped with alternation of activated carbon coated electrodes and dielectric panels in pilot plant, J. Korean Soc. Environ. Eng., 40(5), 203-210(2018).

2. J. H. Kim, I. S. Moon, M. Y. Hwang, R. G. Kim, D. Ko, Filtration characteristics of paticulate matter at bag filters coated with PTFE membrane during off-line pulsing, J. Korean Soc. Environ. Eng., 39(7), 391-402(2017).

3. D. G. Jeong, B. S. Kim, M. S. Hong, The effect of cyclone vortex finder configurations on the fine particle collection efficiencies, J. Korean Soc. Environ. Eng., 39(6), 371-376 (2017).

4. J. Y. Lee, I. Kim, Characteristics of a filter module adsorption for fine dust removal on road, J. Korean Soc. Environ. Eng., 39(1), 19-25(2017).

5. F. Mylläri, P. Karjalainen, R. Taipale, P. Aalto, A. Häyrinen, J. Rautiainen, L. Pirjola, R. Hillamo, J. Keskinen, T. Rönkköa, Physical and chemical characteristics of flue-gas particles in a large pulverized fuel-fired power plant boiler during co-combustion of coal and wood pellets, Combust. Flame, 176, 554-566(2017).

6. T. Eidhammer, D. C. Montague, T. Deshler, Determination 
of index of refraction and size of supermicrometer particles from light scattering measurements at two angles, J. Geophys. Res., 113(D16)(2008).

7. B. Zhao, Z. Yan, M. V. Johnston, H. Wang, A. S. Wexler, M. Balthasar, M. Kraft, Measurement and numerical simulation of soot particle size distribution functions in a laminar premixed ethylene-oxygen-argon flame, Combust. Flame, 133(1-2), 173-188(2003).

8. B. Meland, P. D. Kleiber, V. H. Grassian, M. A. Young, Visible light scattering study at 470,550, and $660 \mathrm{~nm}$ of components of mineral dust aerosol: Hematite and goethite, J. Quant. Spectrosc. Ra., 112(6), 1108-1118(2011).

9. S. Amaral, J. de Carvalho, M. Costa, C. Pinheiro, An overview of particulate matter measurement instruments, Atmosphere, 6(9), 1327-1345(2015).

10. L. Chen, Z. Liang, H. Liu, S. Ding, Y. Li, Sensitivity analysis of fuel types and operational parameters on the particulate matter emissions from an aviation piston engine burning heavy fuels, Fuel, 202, 520-528(2017).

11. W. Yuen, Q. Ma, S. Koloutsou-Vakakis, K. Du, M. J. Rood, Lidar equation inversion methods and uncertainties in measuring fugitive particulate matter emission factors, Appl., 56(27), 7691-7701(2017).

12. M. L. McNamara, C. W. Noonan, T. J. Ward, Correction factor for continuous monitoring of wood smoke fine particulate matter, Aerosol Air Qual. Res., 11(3), 315-322(2011).
13. K. N. Liou, An Introduction to Atmospheric Radiation, 2nd ed., Elsevier(2002).

14. L. Pottier, J. Pruvost, J. Deremetz, J.-F, Cornet, J. Legrand, C. G. Dussap, A fully predictive model for one-dimensional light attenuation by Chlamydomonas reinhardtii in a torus photobioreactor, Biotechnol. Bioeng., 91(5), 569-582(2005).

15. M. F. Modest, Radiative Heat Transfer, 3rd ed. Academic Press(2013).

16. F. Liu, B. J. Stagg, D. R. Snelling, G. J. Smallwood, Effects of primary soot particle size distribution on the temperature of soot particles heated by a nanosecond pulsed laser in an atmospheric laminar diffusion flame, Int. J. Heat Mass Transf., 49(3-4), 777-788(2006).

17. C. Verhaege, V. Shcherbakov, P. Personne, Limitations on retrieval of complex refractive index of spherical particles from scattering measurements, J. Quant. Spectrosc. Ra., 109(14), 2338-2348(2008).

18. B.-J. Gong, P.-M. Park, J.-I. Dong, PM10 emission estimation from LNG G/T power plants and its important analysis on air quality in Incheon Area, J. Korean Soc. Atmos. Environ., 31(5), 461-471(2015).

19. J. Y. Zhang, H. Qi, Y. T. Ren, L. M. Ruan, Simultaneous identification of optical constants and PSD of spherical particles by multi-wavelength scattering - transmittance measurement, Opt. Commun., 413(12), 317-328(2018). 